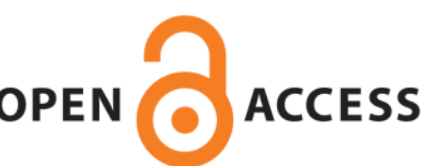

UWS Academic Portal

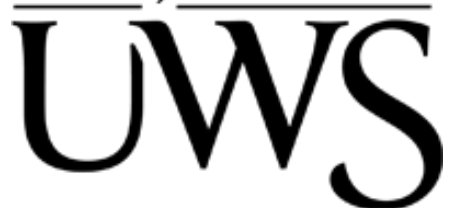

\title{
Evidence from prospective cohort studies does not support current dietary fat guidelines: a systematic review and meta-analysis
}

Harcombe, Zoë; Baker, Julien S.; Davies, Bruce

Published in:

British Journal of Sports Medicine

DOI:

10.1136/bjsports-2016-096550

E-pub ahead of print: 03/10/2016

Document Version

Peer reviewed version

Link to publication on the UWS Academic Portal

Citation for published version (APA):

Harcombe, Z., Baker, J. S., \& Davies, B. (2016). Evidence from prospective cohort studies does not support current dietary fat guidelines: a systematic review and meta-analysis. British Journal of Sports Medicine, 51(24). https://doi.org/10.1136/bjsports-2016-096550

\section{General rights}

Copyright and moral rights for the publications made accessible in the UWS Academic Portal are retained by the authors and/or other copyright owners and it is a condition of accessing publications that users recognise and abide by the legal requirements associated with these rights.

Take down policy

If you believe that this document breaches copyright please contact pure@uws.ac.uk providing details, and we will remove access to the work immediately and investigate your claim. 


\section{Evidence from prospective cohort studies does not support current dietary fat guidelines: a systematic review and meta-analysis}

\section{Zoë Harcombe ${ }^{1 *}$, Julien S. Baker ${ }^{1}$, Bruce Davies².}

${ }^{1}$ Institute of Clinical Exercise and Health Science, University of the West of Scotland, Hamilton, Lanarkshire, UK; ${ }^{2}$ University of South Wales, Pontypridd, UK.

* Corresponding author Zoë Harcombe. Tel +44 (0)1698 283100. E-mail address: Zoe.Harcombe@uws.ac.uk. Address: Institute of Clinical Exercise and Health Science, University of West of Scotland, 438 Almada Building, Almada Street, Hamilton, Lanarkshire, UK.

MeSH keywords: Public health; heart disease; dietary; cholesterol; cohort study.

Word count, excluding title page, abstract, references, figures and tables: 3,871 . 


\begin{abstract}
(248 words)
Objectives: National dietary guidelines were introduced in 1977 and 1983, by the United States (US) and United Kingdom (UK) governments to reduce coronary heart disease (CHD) mortality by reducing dietary fat intake. Our 2016 systematic review examined the epidemiological evidence available to the dietary committees at the time; we found no support for the recommendations to restrict dietary fat. The present investigation extends our work by re-examining the totality of epidemiological evidence currently available relating to dietary fat guidelines.
\end{abstract}

Methods: A systematic review and meta-analysis of prospective cohort studies currently available, which examined the relationship between dietary fat, serum cholesterol and the development of CHD, were undertaken.

Results: Across 7 studies, involving 89,801 participants (94\% male), there were 2,024 deaths from CHD during the mean follow-up of $11.9 \pm 5.6$ years. The death rate from CHD was $2.25 \%$. Eight data sets were suitable for inclusion in meta-analysis; all excluded participants with previous heart disease.

Risk ratios (RR) from meta-analysis were not statistically significant for CHD deaths and total or saturated fat consumption. The risk ratio (RR) from meta-analysis for total fat intake and CHD deaths was 1.04 (95\% CI 0.98 to 1.10). The RR from meta-analysis for saturated fat intake and CHD deaths was 1.08 (95\% CI 0.94 to 1.25 ).

Conclusions: Epidemiological evidence to date found no significant difference in CHD mortality and total fat or saturated fat intake and thus does not support the present dietary fat guidelines. The evidence per se lacks generalisability for population-wide guidelines. 


\section{Introduction}

US public health dietary advice was announced by the Select Committee on Nutrition and Human needs in 1977[1] and was followed by UK public health dietary advice issued by the National Advisory Committee on Nutritional Education in 1983.[2] Dietary recommendations in both cases focused on reducing dietary fat intake; specifically to i) reduce overall fat consumption to $30 \%$ of total energy intake and ii) reduce saturated fat consumption to $10 \%$ of total energy intake.

The recommendations were intended to address mortality from coronary heart disease (CHD). In 2015, we published a systematic review and meta-analysis,[3] which reported that evidence from randomised controlled trials (RCTs), available to the dietary guideline committees, did not support the introduced dietary fat recommendations. In 2016, we published a systematic review and metaanalysis,[4] which reported that RCT evidence currently available does not support the introduced dietary guidelines. In 2016, we published a systematic review, [5] which reported that epidemiological evidence, available to the dietary guideline committees, did not support the introduced dietary fat recommendations. The aim of these systematic reviews has been twofold: to examine the epidemiological and RCT evidence base for the dietary fat guidelines to assess if they were justified at the time of their introduction and to review if the evidence currently available supports the extant recommendations. This systematic review and meta-analysis completes this work by examining the totality of epidemiological evidence currently available.

\section{Methods}

This systematic review and meta-analysis uses the Meta-analysis Of Observational Studies in Epidemiology methodology (MOOSE).[6] MOOSE uses parts of the Cochrane methodology for systematic review and meta-analysis of RCTs, Preferred Reporting Items for Systematic reviews and Meta-Analyses (PRISMA), for example the figure for presenting search methodology.[7] To examine best practice evidence available, this review has focused on prospective cohort studies.[8]

\section{Search strategy}

A search was undertaken to identify prospective cohort studies that examined the relationship between dietary fat intake, serum cholesterol and mortality from CHD. Exclusion criteria were: clinical trials; cross-sectional studies; case control studies. Inclusion criteria were: prospective cohort studies; participants were human adults; primary study outcome was CHD mortality; data related to dietary fat consumption were available; data on CHD mortality and serum cholesterol measurements were available.

The search was undertaken on 30 September 2015. No date limitations were set, enabling the earliest possible papers to be included. Searches of the literature were performed using MEDLINE, Embase and the Cochrane Library (Fig. 1).

\section{Selection of studies}

Of 669 identified articles, 607 were rejected upon review of the title and abstract. Of these, 55 were rejected for being review articles. 55 were commentaries, editorials or letters. 39 were clinical trials, 9 were cross sectional or case control studies. 75 related to conditions other than heart disease, primarily cancer, diabetes, hypertension and obesity. There were 53 studies in which animals or children/adolescents were the primary focus. 98 were articles about pharmacology/blood analysis. 123 were rejected for being related to a particular food, nutrient or supplement, rather than dietary fat. A further 40 papers were educational material and 36 reviewed dietary compliance in nutritional studies. 24 articles were mathematical modelling exercises, including meta-analysis. 62 papers remained. 13 were rejected on closer inspection of the full paper: 12 were reviews, commentaries or expert opinion pieces and 1 was educational material. Where an abstract was unavailable, the publication type, journal name and meta-tags were reviewed to assess if the article should be rejected (for example "letter", "clinical trial", "paediatric"). Copies of the remaining articles were 
obtained from university libraries or the British Library. 49 papers, prima facie, met the inclusion criteria.

Of the 49 papers included in qualitative synthesis, 18 were found prima facie to meet the inclusion criteria and 31 were duplications of these 18 studies. On detailed examination of the 18 studies, 6 were the studies included in Harcombe et al,[5] which were available to the UK National Advisory Committee in 1983. The Western Electric study;[9 10] The Puerto Rico Heart Health Program;[1113] The Seven Countries Study;[14] The Framingham Heart Study;[11 15] The Honolulu Heart Program;[11 16 17] and a study conducted in London and the South East.[18] None of these had data conducive to meta-analysis. 24 papers were additional publications related to these 6 studies; the majority of these were about The Seven Countries Study. The additional publications were examined for data published after the introduction of the dietary fat guidelines to assess if any Harcombe et al[5] studies could be updated. A 1984 paper about The Honolulu Heart Program[19] and a 1991 paper about The Framingham Heart Study[20] were reviewed, but neither reported CHD mortality.

A total of 12 new studies were found.[21-32] Seven papers were additional publications related to these studies. Four studies were excluded on closer inspection for not reporting CHD mortality data[22 2325 26] and another one contained CHD mortality data that were not separable from CHD events.[24] These five studies also failed to meet inclusion criteria for other reasons: no saturated fat data;[22 26] no total fat data;[25 26] no serum cholesterol data.[22-24 26] Mann et al was the only study to review animal fat, not all dietary fat.[26] This study, examining the benefits of a vegetarian diet, reported consumption of total animal fat and saturated animal fat, thus excluding the fat and saturated fat in many non-animal foods.[33]

Six studies did not report serum cholesterol data,[21 2728 30-32] which left one study meeting the full inclusion criteria.[29] The serum cholesterol component part of the diet-heart hypothesis was set aside as an inclusion criterion, which enabled data for dietary fat (total and saturated) and CHD mortality to be examined for seven studies.[21 27-32] The UK Health survey[21] presented data for men and women separately and The Strong Heart Study of American Indians[31] presented data for those aged 47-59 years and those aged 60-79 separately. Table 1 presents the extracted data for total and saturated dietary fat and CHD deaths for these seven studies; nine information sets.

To ascertain the validity of eligible observational studies, a pair of reviewers (ZH and BD) worked independently to determine which studies met the inclusion criteria. The same one additional study was agreed upon as meeting the original diet-heart hypothesis criteria and the same seven studies were agreed upon for the revised search. One of the authors $(\mathrm{ZH})$ examined contemporary systematic reviews of prospective cohort studies [34-36] to ensure that no studies had been omitted or included inconsistently. Correspondence was entered into with one author for thorough verification. [37] Risk of bias was assessed using the Cochrane Collaboration assessment tool for component parts relevant to observational studies, defined as follows: selection bias (cohort appropriately reflected wider population characteristics); detection bias (blinding of outcome assessment); attrition bias (incomplete data outcome); and reporting bias (selective reporting) (Fig. 2).[38]

\section{Data Extraction}

Table 1 details data extraction of: study name; year of key publications; participant characteristics; whether free from CHD at study entry; years of follow-up; CHD deaths; outcomes relating to total dietary fat and saturated dietary fat for CHD deaths.

\section{Statistical Analysis}

The overall pooled effect was calculated using random effects meta-analysis. This takes into account between study variance when assigning weights in meta-analysis. The weighting of studies is more balanced with random effects than fixed effects methodology; larger studies have less impact and smaller studies have more impact than with fixed effects. Heterogeneity and bias were 
quantified using the $\mathrm{I}^{2}$ and $\mathrm{T}^{2}$ calculations, $\mathrm{I}^{2}=100 \% \times(\mathrm{Q}-d f) / \mathrm{Q}$, where $\mathrm{Q}$ is Cochran's heterogeneity statistic and $d f$ the degrees of freedom. Funnel plot methodology and Egger's regression intercept[39 40] were calculated to assess risk of publication bias. Analyses were performed using Comprehensive Meta-Analysis.[41]

Meta-analysis was possible for all but one study in Table 1.[27] Kushi et al reported fat intake as a percentage of overall energy intake for those who died from CHD and those who did not. However, no standard deviations or standard errors were presented, which are necessary for inclusion in metaanalysis. Forest plots for the associations between CHD deaths and total fat and saturated fat are presented in Fig. 3 and Fig. 4 respectively. 
Fig. 1 Summary of systematic review profile[7].

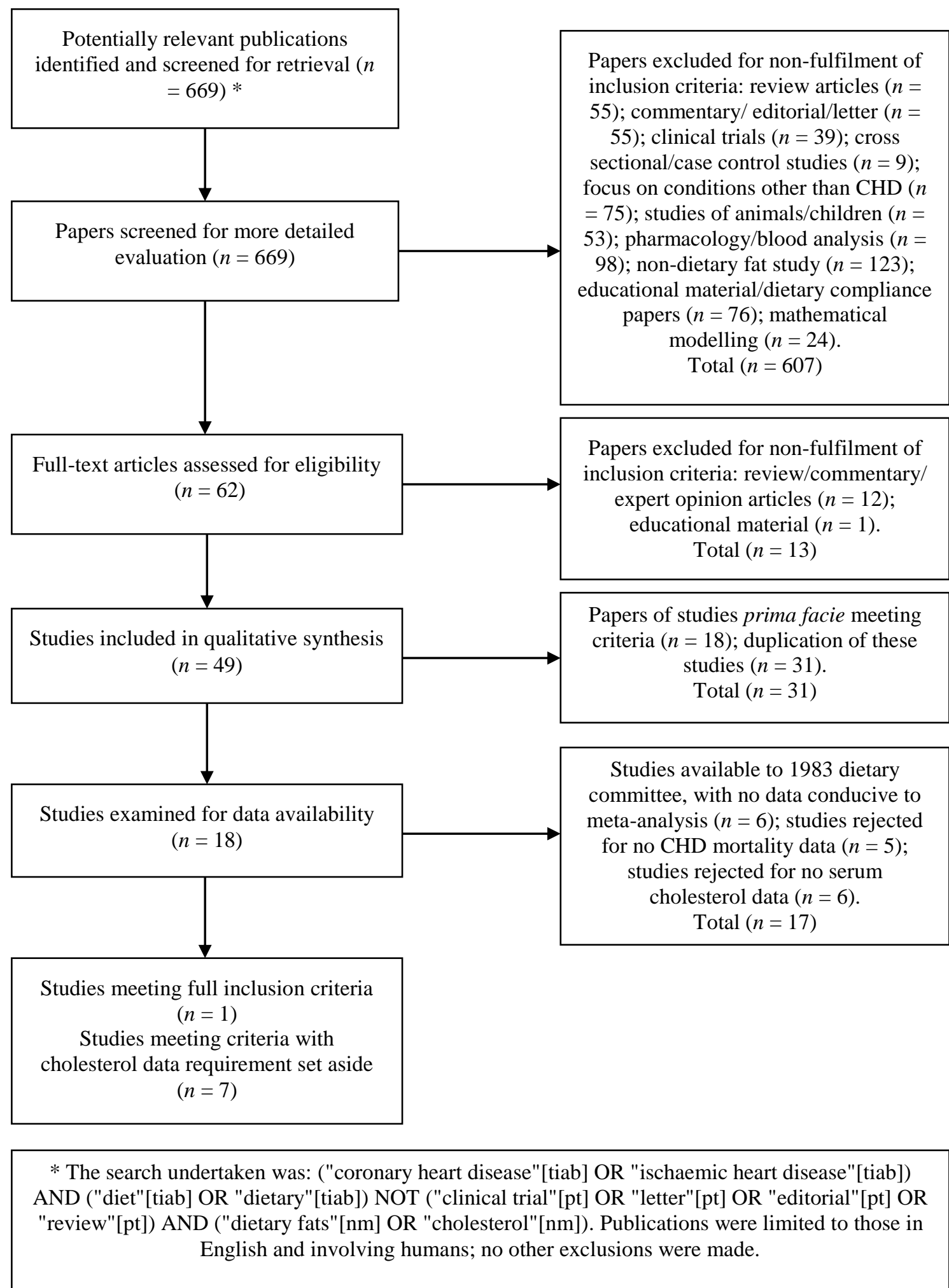


Table 1 Outcome data from prospective cohort studies for: study name; participant number, gender and age range; years of follow-up; total fat and saturated fat for CHD deaths vs. CHD-free.

\begin{tabular}{|c|c|c|c|c|c|c|}
\hline Study & $\begin{array}{l}\text { Men/Women } \\
\text { /Age }\end{array}$ & $\begin{array}{l}\text { CHD- } \\
\text { free? }\end{array}$ & $\begin{array}{l}\text { Follow- } \\
\text { up yrs }\end{array}$ & $\begin{array}{l}\text { CHD } \\
\text { deaths }\end{array}$ & $\begin{array}{c}\text { Total fat } \\
\text { CHD death/Non }\end{array}$ & $\begin{array}{c}\text { Sat fat } \\
\text { CHD death/Non }\end{array}$ \\
\hline $\begin{array}{l}\text { Kushi et al, } \\
\text { Ireland Boston } \\
\text { study[27] (1985) }\end{array}$ & $\begin{array}{c}1,001 \mathrm{M} \\
(30-69)\end{array}$ & $\mathrm{N}$ & 20 & 110 & $\begin{array}{c}39.4 / 38.5 \\
\% \text { energy }(*)\end{array}$ & $\begin{array}{c}17.4 / 16.9 \\
\% \text { energy }(*)\end{array}$ \\
\hline $\begin{array}{l}\text { Ascherio et al, } \\
\text { US Health } \\
\text { Professionals[28] } \\
\text { (1996) }\end{array}$ & $\begin{array}{c}43,757 \mathrm{M} \\
(40-75)\end{array}$ & $\mathrm{Y}$ & 6 & 229 & $\begin{array}{c}\text { Note } 1 \\
1.59(1.01-2.51) \\
(p=0.02)\end{array}$ & $\begin{array}{c}\text { Note } 1 \\
2.21(1.38-3.54) \\
(p=0.0016)\end{array}$ \\
\hline \multirow{2}{*}{$\begin{array}{l}\text { Esrey et al, } \\
\text { Lipid Research } \\
\text { [29] (1996) }\end{array}$} & $\begin{array}{c}2,071 \mathrm{M} \\
1,854 \mathrm{~W} \\
(30-59)\end{array}$ & $\mathrm{Y}$ & 12 & 52 & $\begin{array}{c}\text { Note } 2 \mathrm{a} \\
1.04(1.01-1.08) \\
(p<0.01)\end{array}$ & $\begin{array}{c}\text { Note } 2 \mathrm{a} \\
1.11(1.04-1.18) \\
(\mathrm{p}<0.01)\end{array}$ \\
\hline & $\begin{array}{l}282 \mathrm{M} \\
339 \mathrm{~W} \\
(60-79) \\
\end{array}$ & $\mathrm{Y}$ & 12 & 40 & $\begin{array}{c}\text { Note } 2 \mathrm{a} \\
1.00(0.96-1.04) \\
(p<0.01)(*) \\
\end{array}$ & $\begin{array}{c}\text { Note } 2 \mathrm{a} \\
0.97(0.89-1.05) \\
(\mathrm{p}<0.01)(*)\end{array}$ \\
\hline $\begin{array}{l}\text { Pietinen et al, } \\
\text { The Finnish } \\
\text { Cancer Study } \\
\text { [30] (1997) }\end{array}$ & $\begin{array}{c}21,930 \mathrm{M} \\
(50-69)\end{array}$ & $\begin{array}{c}\mathrm{Y} \text { (all } \\
\text { smokers) }\end{array}$ & 6.1 & 635 & $\begin{array}{c}\text { Note } 1 \\
0.85(0.65-1.12) \\
(*)\end{array}$ & $\begin{array}{c}\text { Note } 1 \\
0.73(0.56-0.95) \\
(p=0.044)\end{array}$ \\
\hline \multirow{2}{*}{$\begin{array}{l}\text { Boniface \& } \\
\text { Tefft, } \\
\text { UK Health } \\
\text { Survey[21] } \\
(2002)\end{array}$} & $\begin{array}{r}1,225 \mathrm{M} \\
(40-75)\end{array}$ & $\mathrm{Y}$ & 16 & 98 & $\begin{array}{c}\text { Note } 2 \mathrm{~b} \\
1.01(0.93-1.10) \\
(*)\end{array}$ & $\begin{array}{c}\text { Note } 2 \mathrm{~b} \\
1.00(0.86-1.18) \\
(*)\end{array}$ \\
\hline & $\begin{array}{c}1,451 \mathrm{~W} \\
(40-75)\end{array}$ & $\mathrm{Y}$ & 16 & 57 & $\begin{array}{c}\text { Note } 2 \mathrm{~b} \\
1.19(1.03-1.37) \\
(p=0.0181)\end{array}$ & $\begin{array}{c}\text { Note } 2 b \\
1.40(1.09-1.79) \\
(p=0.0074)\end{array}$ \\
\hline \multirow{2}{*}{$\begin{array}{l}\text { Xu et al, } \\
\text { Strong Heart } \\
\text { Study[31] } \\
(2006)\end{array}$} & $\begin{array}{c}646 \mathrm{M} \\
1,013 \mathrm{~W} \\
(47-59)\end{array}$ & $\mathrm{Y}$ & 7.2 & 46 & $\begin{array}{c}\text { Note } 3 \\
3.57(1.21-10.49) \\
(p=0.01)\end{array}$ & $\begin{array}{c}\text { Note } 3 \\
5.17(1.64-16.36) \\
(p=0.01)\end{array}$ \\
\hline & $\begin{array}{l}405 \mathrm{M} \\
874 \mathrm{~W} \\
(60-79)\end{array}$ & $\mathrm{Y}$ & 7.2 & 92 & $\begin{array}{c}\text { Note } 3 \\
0.77(0.41-1.45) \\
(*)\end{array}$ & $\begin{array}{c}\text { Note } 3 \\
0.80(0.41-1.54) \\
(*)\end{array}$ \\
\hline $\begin{array}{l}\text { Nagata et al, } \\
\text { Japanese } \\
\text { Study[32] (2012) }\end{array}$ & $\begin{array}{c}12,953 \mathrm{M} \\
(>=35)\end{array}$ & $\mathrm{Y}$ & 16 & 665 & $\begin{array}{c}\text { Notes } 1 \& 4 \\
1.12(0.80-1.57) \\
(*)\end{array}$ & $\begin{array}{c}\text { Notes } 1 \& 4 \\
0.96(0.67-1.39) \\
(*)\end{array}$ \\
\hline TOTAL & 89,801 & & & 2,024 & & \\
\hline
\end{tabular}

Table notes: (*) Not statistically significant

95\% confidence intervals in parentheses.

Note 1: Data were presented in quintiles. The lowest quintile fat intake was given a risk ratio (RR) for CHD mortality of 1.0. The RR for the highest fat intake, quintile 5, was presented.

Note 2: 2a) This presented the RR for a one unit increase in the percentage of energy intake provided by the nutrient.[29] 2b) This was defined as an additional 100 grams per week.[21]

Note 3: Data were presented in quartiles. The lowest quartile fat intake was given a risk ratio (RR) for CHD mortality of 1.0. The RR for the highest fat intake, quartile 4, was presented. 
Note 4: Data are for cardiovascular disease (CVD), not CHD. Nagata et al included 15,403 women, but did not report on CVD, or CHD mortality by fat intake for women (table 4, p.1718 for men)[32]. 
Fig. 2 Methodological quality summary: review authors' judgements about each methodological quality item for each included study.[38]

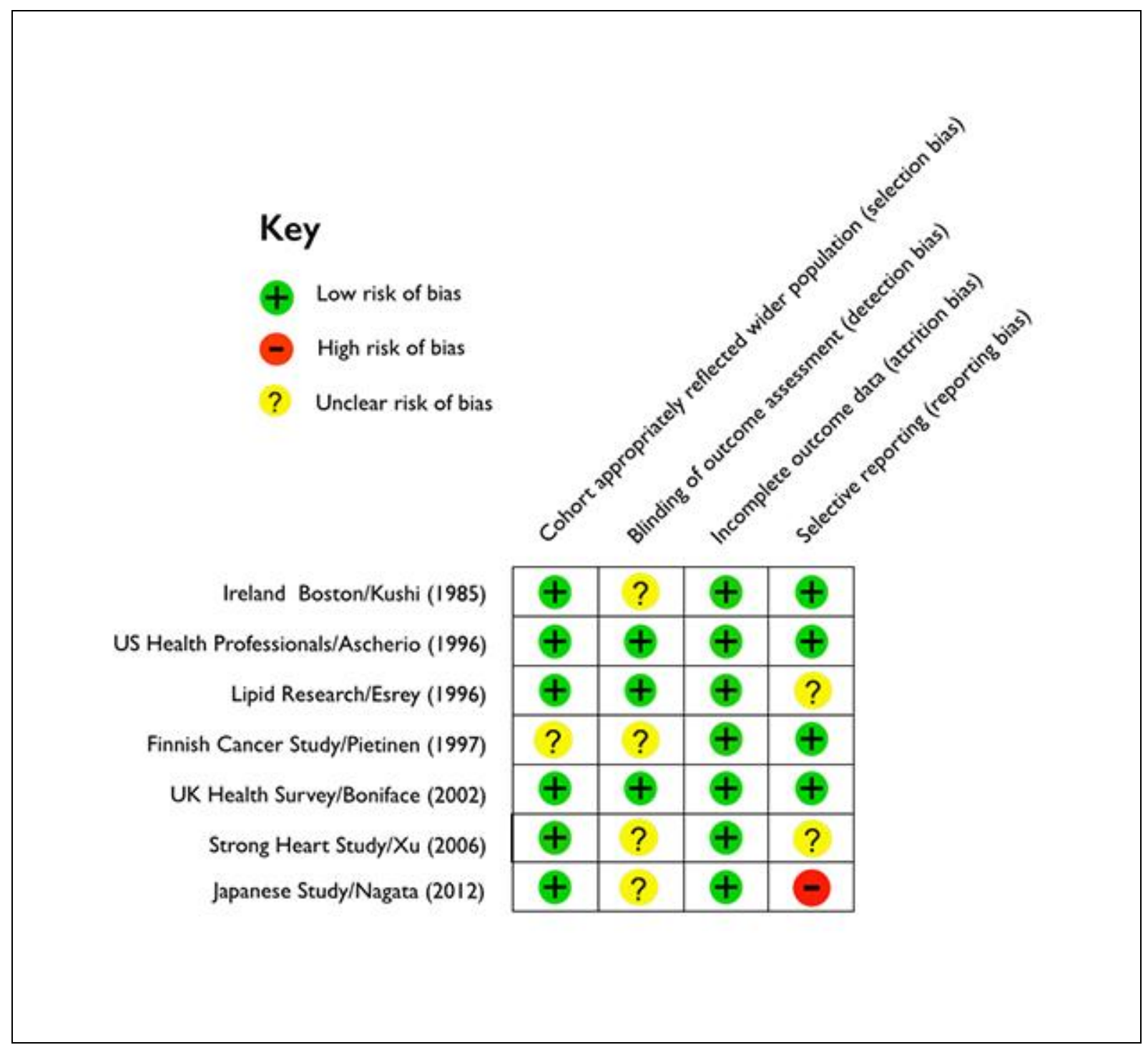

\section{Results: Meta-analysis}

\section{Participants and Study Design}

The seven prospective cohort studies in Table 1 included 89,801 participants. 84,270 of the participants were male (94\%). All but one study excluded people with previous heart disease.[27] This study could not be included in the meta-analysis, as it did not contain suitable data. The age ranges varied from 30 to 79 years old at baseline. Xu et al grouped subjects from 47 to 59 years old and from 60 to 79 years old.[31] No explanation was given for this grouping. Esrey et al grouped subjects from 30 to 59 years old and from 60 to 79 years old.[29] The rationale for this arbitrary classification was reported as to maximise deaths in each group. 
Participants were followed for a minimum of 6 years and a maximum of 20 years. The mean duration of the seven cohorts was $11.9 \pm 5.6$ years. The weighted mean duration (person years by participants) was $8.3 \pm 1.1$ years.

All trials had complete outcome data, avoiding attrition bias (Fig. 2).[38] One study was judged unclear for selection bias, as participants excluded non-smokers.[30] Four studies were judged unclear for detection bias, as blinding of outcome assessment was unclear.[27 30-32] Risk of reporting bias was judged low for four of the studies: it was judged unclear for The Strong Heart Study and The Lipid Research Study, as the rationale for the age group divisions were not clear;[29 31] and it was judged high risk for the Japanese Study as CVD by fat intake was researched, but not reported, for women.[32] (Fig. 2)

For total fat and CHD deaths, Esrey et al carried the greatest weight, $31.76 \%$ for the 30 to 59 age group and $29.45 \%$ for the 60 to 79 age group (Fig. 3 random effects methodology).[29] The two Boniface and Tefft observations, for men and women, carried a combined weight of 30.04\%.[21] The two $\mathrm{Xu}$ et al observations carried a weight of $1.02 \%$ between them.[31] The risk ratio for the meta-analysis of the eight data sets available for total fat and CHD deaths was 1.04 (95\% CI 0.98 to 1.10). The overall effect measurement lies on the line of no effect. There was no statistically significant difference between total fat and CHD deaths.

The meta-analysis for total fat and CHD deaths was tested for sensitivity analysis of the exclusion of any one study. There were no circumstances in which the exclusion of any one study made the overall effect size significant.

There was evidence for between study heterogeneity. The Q-value was $18.218(8 d f)$ and this was statistically significant $p=0.020 \mathrm{I}^{2}$ was 56.087 and $\mathrm{T}^{2}$ was 0.002 indicating difference in true effects.

Visual inspection of the funnel plot revealed that one study was outside the standard error funnel for the meta-analysis of total fat and CHD deaths. This was the $\mathrm{Xu}$ et al study for people aged 4759,[31] which was substantially different from other risk ratios. The Egger's regression test indicated no statistically significant asymmetry for total fat and CHD deaths. The Egger's regression intercept was 0.640 (95\% CI, two-tailed, -0.959 to 2.238 ), but this was not statistically significant (one-tailed $p=0.188$; two-tailed $p=0.376$ ).

For saturated fat and CHD deaths, Esrey et al carried the greatest weight, $19.83 \%$ for the 30 to 59 age group and $19.28 \%$ for the 60 to 79 age group (Fig. 4 random effects methodology).[29] The two Boniface and Tefft observations, for men and women, carried a combined weight of 28.96\%.[21] The two Xu et al observations carried a weight of 5.10\% between them.[31] The risk ratio for the meta-analysis of the eight data sets available for saturated fat and CHD deaths was 1.08 (95\% CI 0.94 to 1.25 ). The overall effect measurement lies on the line of no effect. There was no statistically significant difference between saturated fat and CHD deaths.

The meta-analysis for saturated fat and CHD deaths was tested for sensitivity analysis of the exclusion of any one study. There were no circumstances in which the exclusion of any one study made the overall effect size significant.

There was evidence for between study heterogeneity. The Q-value was $37.080(8 d f)$ and this was statistically significant $p<0.001 . \mathrm{I}^{2}$ was 78.425 and $\mathrm{T}^{2}$ was 0.025 indicating difference in true effects.

Visual inspection of the funnel plot revealed that three studies were outside the standard error funnel for the meta-analysis of total fat and CHD deaths[28 30] and the Xu et al study for people aged 47-59.[31] The Egger's regression test indicated no statistically significant asymmetry for saturated fat and CHD deaths. The Egger's regression intercept was 0.686 (95\% CI, two-tailed, 1.978 to 3.351), but this was not statistically significant (one-tailed $p=0.281$; two-tailed $p=0.562$ ). 
Fig. 3 Estimates of CHD mortality and total fat risk ratios (95\% confidence intervals) from metaanalysis.

\section{CHD Deaths \& Total Fat Risk Ratios}

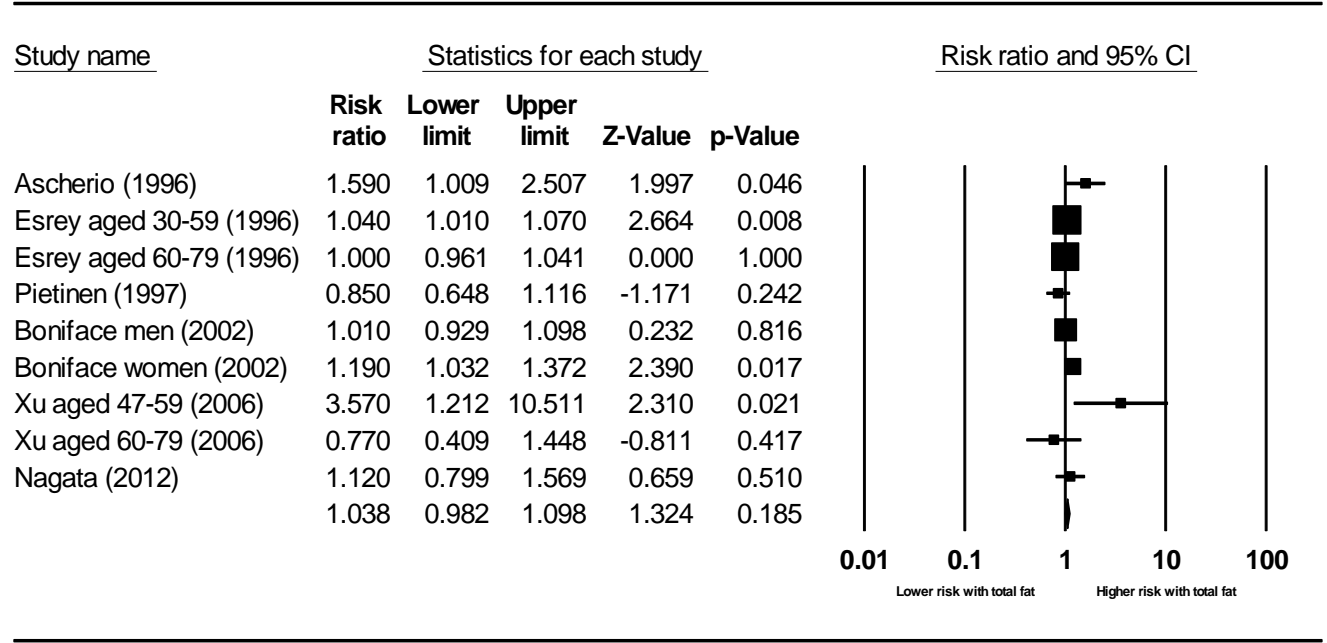

Meta Analysis random effects method

Fig. 4 Estimates of CHD mortality and saturated fat risk ratios (95\% confidence intervals) from meta-analysis.

\section{CHD Death \& Saturated Fat Risk Ratios}

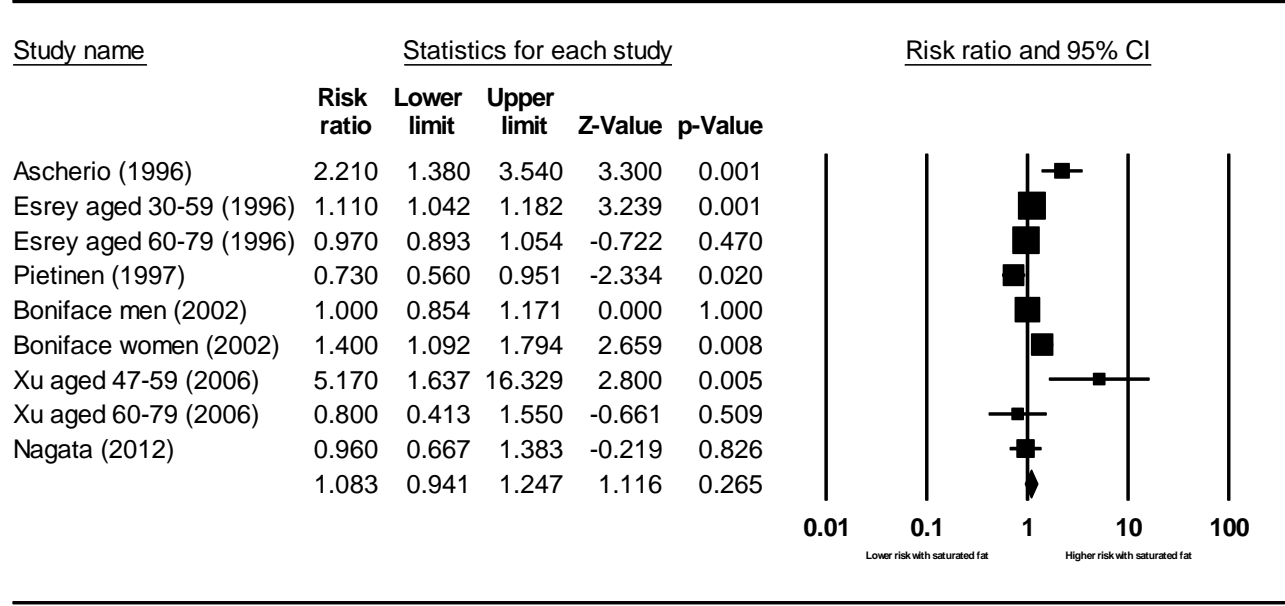

Meta Analysis random effects method 


\section{Examination of the dietary guidelines}

None of the seven cohort studies examined either of the introduced dietary guidelines: a total fat consumption of $30 \%$, or a saturated fat consumption of $10 \%$, of energy intake. Two studies examined the total fat intake and the saturated fat intake, as a percentage of calorie intake, for participants who died from CHD compared with those who did not.[27 29] Esrey et al also reported the risk ratio for an additional one unit of total or saturated fat as a percentage of energy intake. Three studies measured total and saturated fat intake in quintiles and reported data for CHD mortality as risk ratios comparing the lowest and highest quintiles of intake.[28 30 32] The Strong Heart Study followed this method, but for quartiles, not quintiles.[31] The remaining study reported the risk ratio for an additional 100 grams of total or saturated fat per week for men and women separately.[21]

\section{CHD mortality}

Across 7 studies, involving 89,801 participants, there were 2,024 deaths from CHD during the period of follow-up. The death rate from CHD was $2.25 \%$, during the mean follow-up of $11.9 \pm 5.6$ years. The death rate was influenced by the large Finnish study, which included only participants who smoked. The death rate for this study was $2.9 \%$.

The death rate contrasts with the $30 \%$ death rate for the six RCTs reviewed in Harcombe et al[3], which reinforced the high death rate in secondary studies. The one study that included men with previous heart disease reported a death rate of $11 \%$.[27]

\section{Significance reported by the studies}

Three of the seven studies reported some participants separately: two by age groups[29 31] and one by gender.[21] This enabled 10 sets of data to be examined (nine in meta-analysis) (Table 1). Six found no significant relationship between total fat and CHD mortality,[27 30 32] men in the UK health and lifestyle survey[21] men and women aged 60 to 79 years in The Lipid Research Study[29] and the participants aged 60 to 79 years from The Strong Heart Study.[31] The remaining four found a significant relationship between total fat and CHD mortality: Ascherio et al;;28] women in the UK health and lifestyle survey;[21] and the < 60 year old participants from The Lipid Research and The Strong Heart Study.[29 31]Five found no significant relationship between saturated fat and CHD mortality;[27 32] men in the UK health and lifestyle survey;[21] and the participants aged 60 to 79 years from The Lipid Research and The Strong Heart Study.[29 31]The remaining five found a significant relationship between saturated fat and CHD mortality;[28-30] women in the UK health and lifestyle survey;[21] and the under 60 year old participants in The Lipid Research and The Strong Heart Study.[29 31]

Meta-analysis confirmed that the pooled data were not significant for CHD mortality and total fat intake or CHD mortality and saturated fat intake.

\section{Serum cholesterol levels}

The only study to meet the full systematic review inclusion criteria was Esrey et al.[29] This study found a significant relationship between baseline serum cholesterol and subsequent mortality from CHD in the age group 30 to 59 years, but not in the age group 60-79 years old.

\section{Discussion}

The main findings of this systematic review and meta-analysis are that the epidemiological evidence currently available to the dietary committees provides no statistically significant retrospective support for the introduction of dietary fat guidelines.

Most studies reported other significant findings: Kushi et al found a significant association with higher intake of carbohydrate and fiber and lower CHD mortality. Esrey et al found significant positive associations with age, male gender, Body Mass Index (BMI), smoking and CHD deaths. Two studies reported significant associations with trans fat intake and CHD mortality.[28 30] 
Pietinen et al additionally reported significant associations with the number of cigarettes smoked per day, the number of years of smoking, blood pressure, BMI and CHD mortality. Pietinen et al found that High Density Lipoprotein (HDL) cholesterol, education and physical activity were inversely related to the risk of CHD. Ascherio et al found that associations found between dietary fat and heart disease were greatly attenuated by adjusting for fibre intake. Boniface and Tefft reported that smoking, not exercising and being socially disadvantaged were related to higher saturated fat intake and CHD death, which meant that confounding variables could have played a part in findings. $\mathrm{Xu}$ et al found that age, being male, having diabetes and smoking were all significantly associated with CHD deaths.

\section{Design limitations}

As was found with the review of RCT evidence in Harcombe et al[3 4], the fundamental design limitation of epidemiological evidence currently available is that it lacks generalisability. RCT evidence available to the dietary guideline committees had studied men with pre-existing heart disease;[3] epidemiological evidence available to the dietary guideline committees had studied men mostly free from heart disease.[5] One RCT currently available included men and women, without previous heart disease, and contained all component parts of the diet-heart hypothesis for examination.[42] One prospective cohort study currently available included men and women free from heart disease and contained all component parts of the diet-heart hypothesis for examination.[29]

The method of extracting dietary information was a limitation. Dietary recall is generally unreliable and 24-hour recall may not be representative of usual diet.[43 44] Dietary surveys, where food is weighed at the time of being recorded, are also unreliable.[45 46]

\section{Study conclusions}

Two studies concluded that evidence was strong for an association between dietary fat and death from CHD. Boniface and Tefft reported: "Strong evidence was found for the within cohort relationship of dietary fat and CHD death in women while no evidence was found for a relationship in men" (p.786).[21] Xu et al found that: "Total fat, saturated fatty acid, and monounsaturated fatty acid intake were strong predictors of CHD mortality in American Indians aged 47-59 y" (p.894).[31]

The Japanese Study found: "Total fat intake is associated with decreased mortality in Japanese men but not in women" (p.1713).[32]

Two studies reported weak or no associations between dietary fat and CHD mortality. Ascherio et al appeared to reference The Seven Countries Study with their comment, "These data do not support the strong association between intake of saturated fat and risk of coronary heart disease suggested by international comparisons" (p.84).[28] Pietinen et al reported that "There was a significant positive association between the intake of trans fatty acids and the risk of coronary death. There was no association between intakes of saturated or cis-monounsaturated fatty acids or linoleic or linolenic acid or dietary cholesterol and the risk of coronary death" (p.876).[30]

The final two studies described the relationship as unclear. Kushi et al concluded: "The nature of the association in this study between dietary lipids and the risk of mortality from coronary heart disease remains unclear" (p.816).[27] The one study meeting all systematic review inclusion criteria reported: "We conclude that future research must be directed toward better understanding the pathway between dietary intake and coronary disease as the current diet-lipid-heart hypothesis may be overly simplistic" (p.211).[29]

\section{Other meta-analyses of prospective cohort studies}

The aim of this systematic review, as part of a series of four, [3-5] has been to evaluate the RCT and prospective cohort evidence base for two specific dietary fat guidelines (30\% and 10\% of energy 
intake in the form of total and saturated fat respectively) at their time of introduction and the present day. This has not previously been undertaken.

A number of other systematic reviews and meta-analyses have been undertaken, which are relevant to the present review.[34-36 47] De Souza et al[47] systematically reviewed saturated, not total, fat including any observational study, not just prospective cohort studies, with mortality as the end point. Siri-Tarino et al[34] undertook a meta-analysis of prospective cohort studies for saturated, not total, fat, with disease as the end point. Chowdhury et al[36] also examined saturated, not total, fat and with disease, not mortality, as the end point, including RCTs and prospective cohort studies in the same review. Skeaff and Miller[35] were closest to this review, and the one reviewing RCTs currently available,[4] having undertaken a systematic review and meta-analysis of RCTs and prospective cohort studies combined, for total and saturated fat, with CHD end points, disease and mortality. This was published in 2009.

De Souza et al concluded: "Saturated fats are not associated with all cause mortality, CVD, CHD, ischemic stroke, or type 2 diabetes, but the evidence is heterogeneous with methodological limitations" (p.1).[47]

The conclusion of Siri-Tarino et al's review was "meta-analysis of prospective epidemiologic studies showed that there is no significant evidence for concluding that dietary saturated fat is associated with an increased risk of CHD or CVD" (p.535).[34]

Chowdhury et al set out to summarise evidence between fatty acids and coronary disease. Their review examined saturated, monounsaturated, polyunsaturated and trans fats, while also reviewing individual chain length fatty acids, palmitic $(\mathrm{C} 16: 0)$ and margaric $(\mathrm{C} 17: 0)$ as examples. The conclusion was "Current evidence does not clearly support cardiovascular guidelines that encourage high consumption of polyunsaturated fatty acids and low consumption of total saturated fats" (p.398) [36].

Skeaff and Miller sought to summarise the evidence from cohort studies and RCTs of the relation between dietary fat and risk of CHD. Their conclusion was "Intake of total fat was not significantly associated with CHD mortality. Intake of total fat was also unrelated to CHD events" (p.175) [35].

Harcombe et al[3 5] found that the dietary fat guidelines were not supported by RCT or epidemiological evidence available at the time of their introduction. These dietary fat guidelines have prevailed until 2016 and thus the validity of their evidence base remains important to examine. UK dietary fat guidelines are unchanged. The Dietary Guidelines for Americans, issued in January 2016,[48] were conspicuously silent on the subject of total fat, but reiterated that saturated fat should be restricted to no more than $10 \%$ of calorie intake. Harcombe et al[4] found that the RCT evidence currently available does not support the dietary fat guidelines. This review finds that the epidemiological evidence currently available does not support the dietary fat guidelines. All systematic reviews found serious limitations with the availability of primary prevention, both-sex, studies, which are the ones most likely to have generalisability for whole populations.

The conclusion of the four systematic reviews and three meta-analyses is that there was no evidence to support the dietary fat guidelines being introduced and there is no evidence currently available to support them. Public health authorities need to urgently review dietary advice.

\section{Funding}

No funding has been sought or received for this article. 


\section{References}

1. Select Committee on Nutrition and Human Needs. Dietary goals for the United States. First ed. Washington: U.S. Govt. Print. Off., February 1977.

2. National Advisory Committee on Nutritional Education (NACNE). A discussion paper on proposals for nutritional guidelines for health education in Britain. London: The Health Education Council, 1983.

3. Harcombe Z, Baker JS, Cooper SM, et al. Evidence from randomised controlled trials did not support the introduction of dietary fat guidelines in 1977 and 1983: a systematic review and meta-analysis. Open Heart 2015;2(1) doi: 10.1136/openhrt-2014-000196[published Online First: Epub Date]|.

4. Harcombe Z, Baker JS, DiNicolantonio JJ, Grace F, Davies B. Evidence from randomised controlled trials does not support current dietary fat guidelines: a systematic review and meta-analysis. Open Heart 2016;3(2) doi: 10.1136/openhrt-2016-000409[published Online First: Epub Date]|.

5. Harcombe Z, Baker JS, Davies B. Evidence from prospective cohort studies did not support the introduction of dietary fat guidelines in 1977 and 1983: a systematic review. Br. J. Sports Med. 2016 doi: 10.1136/bjsports-2016-096409[published Online First: Epub Date]|.

6. Stroup DF, Berlin JA, Morton SC, et al. Meta-analysis of observational studies in epidemiology: A proposal for reporting. JAMA 2000;283(15):2008-12 doi:

10.1001/jama.283.15.2008[published Online First: Epub Date]|.

7. Moher D, Liberati A, Tetzlaff J, Altman DG. Preferred reporting items for systematic reviews and meta-analyses: the PRISMA statement. J. Clin. Epidemiol. 2009;62(10):1006-12 doi: 10.1016/j.jclinepi.2009.06.005[published Online First: Epub Date]|.

8. Song JW, Chung KC. Observational Studies: Cohort and Case-Control Studies. Plast. Reconstr. Surg. 2010;126(6):2234-42 doi: 10.1097/PRS.0b013e3181f44abc[published Online First: Epub Date]|.

9. Paul O, Lepper MH, Phelan WH, et al. A Longitudinal Study of Coronary Heart Disease. Circulation 1963;28(1):20-31 doi: 10.1161/01.cir.28.1.20[published Online First: Epub Date]|.

10. Shekelle RB, Shryock AM, Paul O, et al. Diet, Serum Cholesterol, and Death from Coronary Heart Disease. New England Journal of Medicine 1981;304(2):65-70 doi: doi:10.1056/NEJM198101083040201[published Online First: Epub Date]|.

11. Gordon T, Kagan A, Garcia-Palmieri M, et al. Diet and its relation to coronary heart disease and death in three populations. Circulation 1981;63(3):500-15 doi: 10.1161/01.cir.63.3.500[published Online First: Epub Date]|.

12. Garcia-Palmieri MR, Feliberti M, Costas R, Jr., et al. An epidemiological study on coronary heart disease in Puerto Rico: The Puerto Rico Heart Health Program. Bol. Asoc. Med. P. R. 1969;61(6):174-9

13. Garcia-Palmieri MR, Tillotson J, Cordero E, et al. Nutrient intake and serum lipids in urban and rural Puerto Rican men. The American journal of clinical nutrition 1977;30(12):2092-100

14. Keys A. Coronary heart disease in seven countries I. The study program and objectives. Circulation 1970;41(I-1-I-8) doi: 10.1161/01.CIR.41.4S1.I-1[published Online First: Epub Date]|.

15. Gordon T, Kannel WB. The Framingham Massachusetts Study twenty years later. In: Kessler I, Levin M, eds. The Community as an Epidemiologic Laboratory; A Casebook of Community Studies. Baltimore: Johns Hopkins Press, 1970:123-46.

16. Kagan A, Harris BR, Winkelstein W, Jr., et al. Epidemiologic studies of coronary heart disease and stroke in Japanese men living in Japan, Hawaii and California: demographic, physical, dietary and biochemical characteristics. J. Chronic Dis. 1974;27(7-8):345-64 
17. Yano K, Rhoads GG, Kagan A, Tillotson J. Dietary intake and the risk of coronary heart disease in Japanese men living in Hawaii. The American journal of clinical nutrition 1978;31(7):1270-9

18. Morris JN, Marr JW, Clayton DG. Diet and heart: a postscript. BMJ 1977;2(6098):1307-14 doi: 10.1136/bmj.2.6098.1307[published Online First: Epub Date]|.

19. McGee DL, Reed DM, Yano K, Kagan A, Tillotson J. Ten-year incidence of Coronary Heart Disease in The Honolulu Heart Program: Relationship to nutrient intake. Am. J. Epidemiol. 1984;119(5):667-76

20. Posner BM, Cobb JL, Belanger AJ, Cupples LA, D'Agostino RB, Stokes J, 3rd. Dietary lipid predictors of coronary heart disease in men. The Framingham Study. Arch. Intern. Med. 1991;151(6):1181-7

21. Boniface DR, Tefft ME. Dietary fats and 16-year coronary heart disease mortality in a cohort of men and women in Great Britain. Eur. J. Clin. Nutr. 2002;56(8):786-92 doi: 10.1038/sj.ejcn.1601509[published Online First: Epub Date]|.

22. Fehily AM, Yarnell JWG, Sweetnam PM, Elwood PC. Diet and incident ischaemic heart disease: the Caerphilly Study. British Journal of Nutrition 1993;69(02):303-14 doi: doi:10.1079/BJN19930035[published Online First: Epub Date]|.

23. Jakobsen MU, Overvad K, Dyerberg J, Schroll M, Heitmann BL. Dietary Fat and Risk of Coronary Heart Disease: Possible Effect Modification by Gender and Age. Am. J. Epidemiol. 2004;160(2):141-49 doi: 10.1093/aje/kwh193[published Online First: Epub Date]|.

24. Oh K, Hu FB, Manson JE, Stampfer MJ, Willett WC. Dietary Fat Intake and Risk of Coronary Heart Disease in Women: 20 Years of Follow-up of the Nurses' Health Study. Am. J. Epidemiol. 2005;161(7):672-79 doi: 10.1093/aje/kwi085[published Online First: Epub Date]|.

25. Goldbourt U, Yaari S, Medalie JH. Factors predictive of long-term coronary heart disease mortality among 10,059 male Israeli civil servants and municipal employees. A 23-year mortality follow-up in the Israeli Ischemic Heart Disease Study. Cardiology 1993;82(23):100-21

26. Mann JI, Appleby PN, Key TJ, Thorogood M. Dietary determinants of ischaemic heart disease in health conscious individuals. Heart 1997;78(5):450-55 doi: 10.1136/hrt.78.5.450[published Online First: Epub Date]|.

27. Kushi LH, Lew RA, Stare FJ, et al. Diet and 20-Year Mortality from Coronary Heart Disease. New England Journal of Medicine 1985;312(13):811-18 doi: doi:10.1056/NEJM198503283121302[published Online First: Epub Date]|.

28. Ascherio A, Rimm EB, Giovannucci EL, Spiegelman D, Meir S, Willett WC. Dietary fat and risk of coronary heart disease in men: cohort follow up study in the United States. BMJ 1996;313(7049):84-90 doi: 10.1136/bmj.313.7049.84[published Online First: Epub Date]|.

29. Esrey KL, Joseph L, Grover SA. Relationship between dietary intake and coronary heart disease mortality: Lipid Research Clinics Prevalence Follow-Up Study. J. Clin. Epidemiol. 1996;49(2):211-16 doi: http://dx.doi.org/10.1016/0895-4356(95)00066-6[published Online First: Epub Date]|.

30. Pietinen P, Ascherio A, Korhonen P, et al. Intake of Fatty Acids and Risk of Coronary Heart Disease in a Cohort of Finnish Men: The Alpha-Tocopherol, Beta-Carotene Cancer Prevention Study. Am. J. Epidemiol. 1997;145(10):876-87

31. Xu J, Eilat-Adar S, Loria C, et al. Dietary fat intake and risk of coronary heart disease: the Strong Heart Study. The American journal of clinical nutrition 2006;84(4):894-902

32. Nagata C, Nakamura K, Wada K, et al. Total Fat Intake Is Associated with Decreased Mortality in Japanese Men but Not in Women. The Journal of Nutrition 2012;142(9):1713-19 doi: 10.3945/jn.112.161661[published Online First: Epub Date]|. 
33. Harcombe Z, Baker J, Davies B. Food for Thought: Have We Been Giving the Wrong Dietary Advice? Food and Nutrition Sciences 2013;4(3):240-44 doi: 10.4236/fns.2013.43032[published Online First: Epub Date]|.

34. Siri-Tarino PW, Sun Q, Hu FB, Krauss RM. Meta-analysis of prospective cohort studies evaluating the association of saturated fat with cardiovascular disease. The American journal of clinical nutrition 2010;91(3):535-46 doi: 10.3945/ajcn.2009.27725[published Online First: Epub Date]|.

35. Skeaff CM, Miller J. Dietary fat and coronary heart disease: summary of evidence from prospective cohort and randomised controlled trials. Ann. Nutr. Metab. 2009;55(1-3):173201 doi: 10.1159/000229002[published Online First: Epub Date]|.

36. Chowdhury R, Warnakula S, Kunutsor S, et al. Association of Dietary, Circulating, and Supplement Fatty Acids With Coronary Risk: A Systematic Review and Meta-analysis. Ann. Intern. Med. 2014;160(6):398-406 doi: 10.7326/M13-1788[published Online First: Epub Date]|.

37. Personal correspondence with Siri-Tarino. Email exchange. In: Harcombe Z, ed., 2015.

38. Higgins JPT, Altman DG, Gøtzsche PC, et al. The Cochrane Collaboration's tool for assessing risk of bias in randomised trials. BMJ 2011;343 doi: 10.1136/bmj.d5928[published Online First: Epub Date]|.

39. Egger M, Smith GD, Schneider M, Minder C. Bias in meta-analysis detected by a simple, graphical test. BMJ 1997;315(7109):629-34 doi: 10.1136/bmj.315.7109.629[published Online First: Epub Date]|.

40. Sterne JAC, Sutton AJ, Ioannidis JPA, et al. Recommendations for examining and interpreting funnel plot asymmetry in meta-analyses of randomised controlled trials. BMJ 2011;343 doi: 10.1136/bmj.d4002[published Online First: Epub Date]|.

41. Borenstein M, Hedges L, Higgins J, Rothstein H. Comprehensive Meta Analysis Version 2. 2 ed. Biostat, Englewood, NJ 2005.

42. Frantz ID, Dawson EA, Ashman PL, et al. Test of effect of lipid lowering by diet on cardiovascular risk. The Minnesota Coronary Survey. Arteriosclerosis, Thrombosis, and Vascular Biology 1989;9(1):129-35 doi: 10.1161/01.atv.9.1.129[published Online First: Epub Date]|.

43. Willett WC. Nutritional epidemiology issues in chronic disease at the turn of the century. Epidemiol. Rev. 2000;22(1):82-6

44. Beaton GH, Milner J, McGuire V, Feather TE, Little JA. Source of variance in 24-hour dietary recall data: implications for nutrition study design and interpretation. Carbohydrate sources, vitamins, and minerals. The American journal of clinical nutrition 1983;37(6):986-95

45. Cook A, Pryer J, Shetty P. The problem of accuracy in dietary surveys. Analysis of the over 65 UK National Diet and Nutrition Survey. J. Epidemiol. Community Health 2000;54(8):61116 doi: 10.1136/jech.54.8.611[published Online First: Epub Date]|.

46. Archer E, Pavela G, Lavie CJ. The Inadmissibility of What We Eat in America and NHANES Dietary Data in Nutrition and Obesity Research and the Scientific Formulation of National Dietary Guidelines. Mayo Clin. Proc. 2015;90(7):911-26 doi: 10.1016/j.mayocp.2015.04.009[published Online First: Epub Date]|.

47. de Souza RJ, Mente A, Maroleanu A, et al. Intake of saturated and trans unsaturated fatty acids and risk of all cause mortality, cardiovascular disease, and type 2 diabetes: systematic review and meta-analysis of observational studies. BMJ 2015;351 doi: 10.1136/bmj.h3978[published Online First: Epub Date]|.

48. U.S. Department of Health and Human Services and U.S. Department of Agriculture. 2015 2020 Dietary Guidelines for Americans. 8th Edition.: Available at http://health.gov/dietaryguidelines/2015/guidelines/. 2015. 